\begin{tabular}{|c|c|c|c|c|c|c|}
\hline \multirow{4}{*}{ Impact Factor: } & ISRA (India) & $=3.117$ & SIS (USA) & $=0.912$ & ICV (Poland) & $=6.630$ \\
\hline & ISI (Dubai, UAE & $=0.829$ & РИНЦ (Russia) & $=0.156$ & PIF (India) & $=1.940$ \\
\hline & GIF (Australia) & $=0.564$ & ESJI $(\mathrm{KZ})$ & $=8.716$ & IBI (India) & $=4.260$ \\
\hline & JIF & $=1.500$ & SJIF (Morocco) & $=5.667$ & OAJI (USA) & $=0.350$ \\
\hline
\end{tabular}

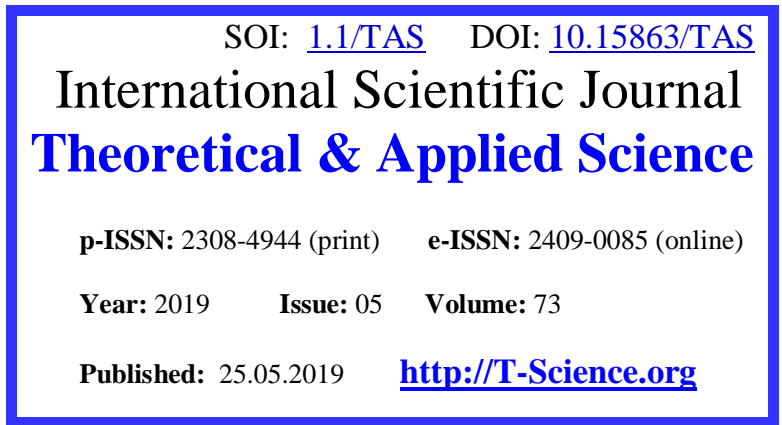

Sociological research.
QR - Issue

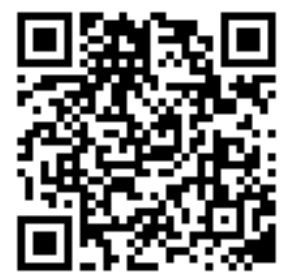

Associate Professor, Doctor of Science of Social Work

\title{
FORMATION OF POSITIVE ATTITUDES TOWARDS PERSONS WITH DISABILITIES IN SOCIAL WORK STUDENTS
}

Abstract: The article presents research for formation positive attitudes towards persons with disabilities in the social work students in educational and social environment with anti-discrimination component. The results of the analysis of empirical data reveal the role and importance of the constructed environment for the development of students in certain fields. An important position among them have: creating a microclimate sensitive to diversity, valuing their significance; conscious and motivated involvement in equal, tolerant and non-discriminatory interactions in different interpersonal and social systems; overcoming stereotypes and prejudices and enhancing cultural competence; promoting the value of diversity and non-discrimination in the academic community and society.

Key words: social work education, model of educational and social environment, persons with disabilities, nondiscrimination, diversity, cultural competence, positive non-discriminatory attitudes.

Language: English

Citation: Nunev, S. T. (2019). Formation of positive attitudes towards persons with disabilities in social work students. ISJ Theoretical \& Applied Science, 05 (73), 301-309.

Soi: http://s-o-i.org/1.1/TAS-05-73-42 Doi: rossef https://dx.doi.org/10.15863/TAS.2019.05.73.42

\section{Introduction}

In the contemporary conditions at national level and at the level of the European Union, the social work education has to respond to many challenges in order to achieve a higher level of accordance with the dynamic social, political, economic and demographic situation and implement training to the students with a high level of responsibility, quality and efficiency. In the outlined context, an important dimension of practicing the social work profession is respect for the value of diversity in the clients' communities and the society, as well as the principles of equality, tolerance and non-discrimination, and their integration into the system of professional competences and professional activity. The realization of the presented aspects requires the construction of an educational and social environment with a specific component characterized by the creation of conditions that contribute to the formation of social work students of positive nondiscriminatory attitudes towards persons with disabilities as one of the most vulnerable communities in terms of poverty, discrimination and social exclusion.
Current national and European antidiscrimination dimensions

In European Parliament documents based on the principles of the United Nations Convention on the Rights of Persons with Disabilities, attention focuses on the sustainable integration of disability issues into all European Union policies and Member States [10]. They are of essential importance for the protection of rights, the fight against discrimination and the sustainable inclusion of persons with disabilities.

An important point in them is the overcoming of stereotypes, prejudices towards persons with disabilities and their discrimination and the effective functioning of an inclusive education and training system. In this context, public attention and reactions of opposition and dealing with problems of discrimination on basis of disability are one of the most dynamic and characterized by professional and social responsibility. Parts of the measures for the development of anti-discrimination policy in the field of disability are associated with active inclusion in education in general and particularly in social work of the following basic questions:

a. diversity of society and the interpretation of disabilities as part of it and in the context of the social 


\begin{tabular}{|c|c|c|c|c|c|c|}
\hline \multirow{4}{*}{ Impact Factor: } & ISRA (India) & $=3.117$ & SIS (USA) & $=0.912$ & ICV (Poland) & $=6.630$ \\
\hline & ISI (Dubai, UAI & $=0.829$ & РИНЦ (Russia & $=0.156$ & PIF (India) & $=1.940$ \\
\hline & GIF (Australia) & $=0.564$ & ESJI (KZ) & $=8.716$ & IBI (India) & $=4.260$ \\
\hline & JIF & $=1.500$ & SJIF (Morocco & $=5.667$ & OAJI (USA) & $=0.350$ \\
\hline
\end{tabular}

model and the model of the rights of persons with disabilities;

b. formation of educational and social environment that includes anti-discrimination component and creates conditions and encourages the use of approaches and models to work to overcome negative attitudes, stereotypes, prejudices and discrimination based on disability and intersecting with it and other signs as well as for effective protection of human rights and overcoming the negative consequences of discrimination.

At local and national level a certain extent of accessibility of university education are achieved, which creates conditions for increasing the share of social work students with disabilities (physical, motor and sensory disabilities) in the universities due to their willingness to training in the social worker profession. Despite the availability of accessible physical and informational environments, the formation of a educational and social environment with a specific component that takes into account the importance of attitudes, stereotypes, prejudices and discrimination on the basis of disability and opportunities for their prevention and overcoming is used to an insufficient extent.

The presented reveals the need to take into account the role of attitudes towards discrimination on basis of various signs, including disability, in social work students as one of the factors which is whit significant potential for impact on their preparation in a general and anti-discrimination aspect. This allows the diversity among of the students (including disabilities) to interpret in the context of the educational and social environment with an antidiscrimination component.

In the social work education in Bulgaria no debates have been held focusing on: awareness and deep understanding of individual and institutional forms of discrimination, their consequences and the ways of preventing and confronting them through institutional mechanisms, methods, approaches and practices; use of techniques, methods and forms of anti-discrimination social work with clients from vulnerable and discriminated groups with certain differences (e.g. race, ethnic origin, gender, gender identity, sexual orientation, age, disability, etc.) corresponding to the specifics of their situation and problems. There are no published results of researches for the attitudes towards persons with disabilities of social work students in the context of an educational and social environment with a specific antidiscrimination component. The current situation allows the research attention to focus on constructing such an educational and social environment, in which conditions positive attitudes towards persons with disabilities formed are in social work students. They is identify as one of factors characterized by the potential for improving the quality and effectiveness of the training of students in social work in a general and anti-discriminatory aspect.

Model of educational and social environment for formation of positive attitudes towards persons with disabilities in social work students

The model of educational and social environment for the formation of positive attitudes towards persons with disabilities in social work students is a construction with a theoretical-applied character. It performs the function of organizing professional thinking and activity in a systematic and effective way and in accordance with the goals, values and the principles of social work in a general and antidiscriminatory aspect.

The design of the model for formation of positive attitudes persons with disabilities in social work students feature a holistic and reflexive approach. The realization of the model characterized by:

a. representation of theories, theoretical directions, theoretical-applied models, techniques, methods, approaches, technologies, functions, roles, skills, activities and interactions in the theoretical and practical training conditions;

b. inclusion of an anti-discrimination component and theoretical-applied models of antidiscrimination social work, which takes into account the specificity of the disciplines from the general and the specialized cycle, their arrangement in chronological and methodological sequence and teaching them through the theoretical content;

c. planning, designing, creating and using simulated situations and participating in real working conditions in practical training and practices.

Structural components of the model of educational and social environment for the formation of positive attitudes towards persons with disabilities in social work students

Context and professional, educational and societal needs, generating necessary to include an anti-discrimination component in social work education.

The actuality and necessity of including an antidiscrimination component in the training of social work students is determined by following group of factors. These factors are associated with: social, political, economic, cultural and demographic contexts; the professional and educational needs of the society in accordance with the national, European and international organizations of social workers and social work education documents on the place and role of anti-discrimination social work in the activities of social workers, education and training in social work and in the implementation of policies and measures to tackle the problems of discrimination in society and the protection and assistance of vulnerable and discriminated groups and their members. Unlike in countries with traditions and experience in including an anti-discrimination component in social work 


\begin{tabular}{|c|c|c|c|c|c|c|}
\hline \multirow{4}{*}{ Impact Factor: } & ISRA (India) & $=3.117$ & SIS (USA) & $=0.912$ & ICV (Poland) & $=6.630$ \\
\hline & ISI (Dubai, UAE & $=0.829$ & РИНЦ (Russia) & $=0.156$ & PIF (India) & $=1.940$ \\
\hline & GIF (Australia) & $=0.564$ & ESJI (KZ) & $=8.716$ & IBI (India) & $=4.260$ \\
\hline & JIF & $=1.500$ & SJIF (Morocco) & $=5.667$ & OAJI (USA) & $=0.350$ \\
\hline
\end{tabular}

education and in the work of social workers, in Bulgaria its integration in the given areas is not clear and is at an early stage of realization. The presented determines the necessary from constructing a model of educational and social environment for formation of positive attitudes towards persons with disabilities in the training and practice of social work students.

Curriculum of the specialties from the professional field "Social work"-forms of curricular and extracurricular activities (theoretical and practical training)

The integration of anti-discriminatory theoretical-applied constructs and models into the curriculum of courses included in the basic cycle and in the social work cycle determined is by the following factors:

a. complex impact of the elements of the previous component of the educational and social environment model;

b. conceptual justification of the curriculum defining the anti-discrimination component as an important and necessary part of its structure and content and its realization as an educational product that meets the current professional, educational and social needs;

c. curriculum content that includes an antidiscrimination component in line with the curriculum concept and the theoretical and practical on social work training implemented through them.

An important element of the structure of this model component is the pedagogical and professional resources of the teachers and social workers-mentors, which enabling students to observe of professional behaviour models and to acquire skills and good experience and practices.

Club forms of extracurricular activity to promote diversity, equality, tolerance and nondiscrimination and to realize interactions with formal and informal social systems

Club forms of extracurricular activity take an important role in structuring and functioning the educational and social environment with an antidiscrimination component in social work to promote diversity, equality, tolerance and non-discrimination, and to overcome negative attitudes, prejudices and discrimination in social work students. In accordance with their purpose and content, they correspond to the highest degree of the concepts included in Gordon Allport's contact hypothesis and the intergroup contact theory $[1 ; 6 ; 7 ; 11 ; 12]$.

The conditions created through it for the realization of positive oriented interpersonal contacts and interactions between representatives of dominant and dominated groups provides certain opportunities. Achieving good mutual understanding and evaluation of differences related to cultural views, lifestyles and models of behaviour contributes to overcome in a constructive way of negative perceptions, attitudes, stereotypes, prejudices and discrimination based on certain signs (e.g. race, ethnic origins, culture, religion, gender, age, disability, etc.). The educational and social environment formed on such a basis characterized by a significant facilitating and encouraging function. This provides an opportunity for restricting and transforming negative attitudes, stereotypes, prejudices and discrimination, generating cognitive, affective, behavioural and social changes and for formation of respecting diversity, tolerant and non-discriminatory interpersonal and inter-group interactions and social relations. In the presented context, the researchers conclude that focused, wellorganized, systematically realized and optimally managed intergroup contacts and interactions are characterized by a progressive reduction of negative attitudes and prejudices, conceptualized into an integrative unity and associated with a wide range of environments and purposed groups on certain signs (e.g. race, ethnic origin, disability, gender, gender identity, sexual orientation, etc.) [12].

The constructed educational and social environment model for forming positive attitudes towards persons with disabilities in social work students in the part about club forms of extracurricular activity includes elements of the theory of intergroup contact and applies them in a specific educational and social context and environment that not been studied. This allows the model as a whole as well as the component club forms of extracurricular activity to defined and function as:

a. important and innovative element of social work education and training in general and in its antidiscriminatory direction;

b. educational and technological antidiscrimination construction involving in the unity and interaction theoretical and practical training in social work, curricular and extracurricular club forms of activity. They are characterized by: absorbing intercultural experience, realizing of direct and indirect social contacts with other groups and their representatives, revealing their positive messages, the desire and their concrete actions for the establishment of equal, tolerant and non-discriminatory relations;

c. educational, social and informational antidiscrimination environment, creating conditions for formal and informal contacts and interactions between members of groups of persons with and without disabilities and between the groups themselves, implementing joint initiatives contributing to their development and building a community and society based on diversity, equality, tolerance and nondiscrimination;

d. an interactive technological educational and social environment whose functioning is characterized by a certain educational, professional and social resonance.

The integration of the presented elements into club forms of extracurricular activity allows achieving a multiplier effect in the social work theoretical and 


\begin{tabular}{|c|c|c|c|c|c|c|}
\hline \multirow{4}{*}{ Impact Factor: } & ISRA (India) & $=3.117$ & SIS (USA) & $=0.912$ & ICV (Poland) & $=6.630$ \\
\hline & ISI (Dubai, UAI & $=0.829$ & РИНЦ (Russia & $=0.156$ & PIF (India) & $=1.940$ \\
\hline & GIF (Australia) & $=0.564$ & ESJI (KZ) & $=8.716$ & IBI (India) & $=4.260$ \\
\hline & JIF & $=1.500$ & SJIF (Morocco & $=5.667$ & OAJI (USA) & $=0.350$ \\
\hline
\end{tabular}

practice training, which contributes to the promotion of diversity, equality, tolerance and nondiscrimination.

The positive educational and social interactions achieved have a cognitive, behavioural and affective effect on the individual, interpersonal, group and intergroup level, and create conditions for the formation of emotional connections, promoting positive and constructive relationships. In the website of the European Association of Schools of Social Work Part of the achievements of an innovative model of educational and social environment with an antidiscrimination component are presented [8;9].

The functioning of educational and social environment is an important prerequisite for student preparation in an anti-discrimination aspect and for their formation as personalities and specialists, who have an active role in building a humane, socially responsible, fair and non-discriminatory society.

\section{Methodology}

Purpose

Identify of the current condition, dynamics and trends of development of the social work students' attitudes towards persons with disabilities in the context of constructed and functioning educational and social environment model with an antidiscrimination component.

\section{Methods}

To identify social work students' attitudes towards persons with disabilities in the context of the model with certain characteristics the Scale for Studying the Attitude towards Disabled Persons has used. Modified it is and adapted to the local conditions version of such type of tool, built on the example of the Scale of Attitudes towards Disabled Persons and is based on the United Nations Convention on the Rights of Persons with Disabilities, disability legislation and policies in the European Union and Bulgaria as a member state $[2 ; 3 ; 4 ; 5]$. Cronbach's alpha coefficient for the research tool is 0.716 and reveals very good reliability and consistency of the items. The scale comprises six fields with the responses for attitudes towards persons with disabilities reported on the five-point Likert scale. It includes the fields with a 34 items.

The scale includes additional positions for obtaining information about factors with the potential to influence the formation of attitudes towards persons with disabilities: gender; identifying with an ethnic community; belonging to a religious community; presence of a person with a disability in the family or in the family environment; presence of disabled friends. This enables to realize an analysis of a wider range.

The research conducted through informed consent of the respondents and in accordance with the principles of voluntary and anonymity. An online form of the tool embedded through a link to the website of the specialty is used (http://socialaffairsru.tk/) is used. The statistical processing and analysis of the data from the research with the IBM SPSS Statistics Version 20 statistical software package is perform.

\section{Respondents}

The research realized out in the academic years 2014-2015 and 2015-2016 with a total 130 students from the Bachelor's and Master's degree in the professional field "Social Work" at University of Ruse. The research involved $111(85.38 \%)$ female gender respondents and 19 (14.62\%) male gender respondents. Participants identifying with the Bulgarian ethnic community are 74 (56.92\%) and participants identifying with a Turkish ethnic community are $56(43.08 \%)$. Belonging to the Christian denomination participants are $68(52.31 \%)$ and participants belonging to the Islamic denomination are 62 (47.69\%). The respondent's whit have a person with a disability in the family or in the family environment are $33(25.38 \%)$ and respondents, which do not have such a member in the family or in the family environment, are 97 (74.62\%). Friends or friends which are disabled have $68 \quad(52,30 \%)$ participants, while $62(47,70 \%)$ of them have no such friend or friends. The members of the Social Workers' Club are 90 (69.23\%) students. The sample contains approximately the peculiarities of the general aggregation, which determines its representativeness.

\section{Results analysis}

Statistical analysis of empirical data by fields of the research tool allows the presentation of the following summarized results for the attitudes towards persons with disabilities, formed in social work students in the context of a certain environment.

1. The established statistically significant difference of the arithmetical mean (Mean) of the summarised assessments with a value of 3 (Test Value $=3$ ) by fields, revealed that for each of them the average value differed statistically credibly from the value of 3 ( $p<0.001)$ with the significance level used $\alpha=0,05$. This is confirmed of the values of the level of significance $\mathrm{p}$.

2. A positive difference between all averages and the value of 3 (Test Value $=3$ ) is established in all fields, revealing the placement of respondents' answers over the neutral position and consistently and predominantly in an left part of the scale of the research tool. This also reveals a high level of explicitness of the expressed opinions and consent the assertion regarding positive attitudes (Table 1).

3. The values of the statistical dimensions (Mean, Median, Mode) representing the central trend in the six fields reveal that a predominant share of the respondents' answers is evaluated with values above the neutral position of the scale of the research tool. Located are steadily and mainly in its left part and express a high level of explicitness and an consent with assertions regarding positive attitudes in the 


\begin{tabular}{|c|c|c|c|c|c|c|}
\hline \multirow{4}{*}{ Impact Factor: } & ISRA (India) & $=3.117$ & SIS (USA) & $=0.912$ & ICV (Poland) & $=6.630$ \\
\hline & ISI (Dubai, UAE & $=0.829$ & РИНЦ (Russia & $=0.156$ & PIF (India) & $=1.940$ \\
\hline & GIF (Australia) & $=0.564$ & ESJI (KZ) & $=8.716$ & IBI (India) & $=4.260$ \\
\hline & JIF & $=1.500$ & SJIF (Morocce & $=5.667$ & OAJI (USA) & $=0.350$ \\
\hline
\end{tabular}

elements included in the fields (Table 2). The dominant place taken by the high numerical values of the Mean, Median, and Mode in all fields. In two of them, they are slightly lower, which is associated with a certain relative share of declared neutral positions. The positive trend is leading and sustainable for all areas.

4. The high numerical values of the statistical dimensions of the arithmetic mean, median and mode, and the established minimum difference between them in each of the six fields, make it possible to predict a tendency for their distribution in a narrower interval. This representing an indicator for concentration and relatively even placing of the majority of the respondents' answers into positions on the left side of the scale of the research tool, related to express positive non-discriminatory attitudes. This also reveals high level of consent and agreement of respondents' answers with to the statements from the elements in the fields and their positive attitudes related to them (Table 2).
5. The standard deviation for all areas has values that reveal a probabilistic distribution of respondents' answers well above the neutral position in the scale of the research tool and in its left-hand part associated with positive non-discriminatory attitudes. On this basis, it is possible to present an assertion of a high level of expressed consent with related to expressed positive statements of non-discriminatory attitudes included in the elements from the individual fields of the research tool (Table 2).

6. The $\mathrm{P}_{25}, \mathrm{P}_{50}$ and $\mathrm{P}_{75}$ percentile values for all fields are located within a range significantly above the neutral position and predominantly occupy the left side of the instrument scale to its upper boundary. This clearly represented in the fields $2,3,5$ and 6 . The information obtained from the statistical analysis in the given direction reveals that there are sufficient statistical arguments to highlight a trend of high level of consent with the statements of the elements in the various fields related to positive non-discriminatory attitudes (Table 2).

Table 1. Verification for a statistically significant difference of Mean, the summarized assessments by fields and a pre-set value (Test Value $=3$ )

\begin{tabular}{|c|c|c|c|c|c|c|}
\hline \multicolumn{7}{|c|}{ One-Sample t-test (Student's t-test) } \\
\hline \multirow{3}{*}{ Field } & \multicolumn{6}{|c|}{ Test Value $=3$} \\
\hline & \multirow[t]{2}{*}{$\mathrm{t}$} & \multirow[t]{2}{*}{ df } & \multirow[t]{2}{*}{ Sig. (2-tailed) } & \multirow[t]{2}{*}{ Mean Difference } & \multicolumn{2}{|c|}{$\begin{array}{l}\text { 95\% Confidence Interval of } \\
\text { the Difference }\end{array}$} \\
\hline & & & & & Lower & Upper \\
\hline Field 1 & 20,586 & 130 & 0,000 & 1,16486 & 1,0525 & 1,2773 \\
\hline Field 2 & 26,956 & 130 & 0,000 & 1,48913 & 1,3794 & 1,5989 \\
\hline Field 3 & 16,922 & 130 & 0,000 & 1,06452 & 0,9396 & 1,1895 \\
\hline Field 4 & 12,407 & 130 & 0,000 & 0,69565 & 0,5843 & 0,8070 \\
\hline Field 5 & 17,725 & 130 & 0,000 & 0,98495 & 0,8746 & 1,0953 \\
\hline Field 6 & 18,746 & 130 & 0,000 & 1,43011 & 1,2786 & 1,5816 \\
\hline
\end{tabular}

Table 2. Values of Mean, Median, Mode and Percentiles by field of the research tool

\begin{tabular}{|l|c|c|c|c|c|c|c|}
\hline \multicolumn{9}{|c|}{ Values of Mean, Median, Mode, Percentiles } \\
\hline \multirow{2}{*}{ Field } & \multirow{2}{*}{ Mean } & \multirow{2}{*}{ Median } & \multirow{2}{*}{ Mode } & \multirow{2}{*}{$\begin{array}{c}\text { Std. } \\
\text { Deviation }\end{array}$} & \multicolumn{3}{c|}{ Percentiles } \\
\cline { 6 - 9 } & & & & & 25 & 50 & 75 \\
\hline Field 1 & 4,1649 & 4,1667 & 4,00 & 0,54274 & 3,8333 & 4,1667 & 4,6667 \\
\hline Field 2 & 4,4891 & 4,6000 & 5,00 & 0,52987 & 4,2000 & 4,6000 & 5,0000 \\
\hline Field 3 & 4,0645 & 4,1429 & 3,86 & 0,60665 & 3,8571 & 4,1429 & 4,5714 \\
\hline Field 4 & 3,6957 & 3,6667 & 3,56 & 0,53778 & 3,3611 & 3,6667 & 4,1111 \\
\hline Field 5 & 3,9849 & 4,0000 & 4,20 & 0,53588 & 3,6000 & 4,0000 & 4,4000 \\
\hline Field 6 & 4,4301 & 4,5000 & 5,00 & 0,73570 & 4,0000 & 4,5000 & 5,0000 \\
\hline
\end{tabular}

7. At all levels was established a distribution of the values of the negative asymmetry factor (Sk) in left polygon. According to the type of distribution of the statements of the respondents' answers in the scale of the research tool, there reason to assert for enough statistical arguments to mark the tendency of positioning the majority of them in its left-hand sector, expressing positive attitudes. The observed trend is most pronounced and confirmed in Fields 1, 2, 3, 5, and 6.

8. The calculated values of Confidence Interval for Mean across all fields allows whit $95 \%$ probability of state that the mean of the results statements for expressing positive attitudes will be within the range 


\begin{tabular}{|c|c|c|c|c|c|c|}
\hline \multirow{4}{*}{ Impact Factor: } & ISRA (India) & $=3.117$ & SIS (USA) & $=0.912$ & ICV (Poland) & $=6.630$ \\
\hline & ISI (Dubai, UAI & $=0.829$ & РИНЦ (Russia & $=0.156$ & PIF (India) & $=1.940$ \\
\hline & GIF (Australia) & $=0.564$ & ESJI (KZ) & $=8.716$ & IBI (India) & $=4.260$ \\
\hline & JIF & $=1.500$ & SJIF (Morocco & $=5.667$ & OAJI (USA) & $=0.350$ \\
\hline
\end{tabular}

of numerical values with ,lower bound - upper bound" above the neutral point and predominantly located in the left part of the scale of the research tool. Statistical information for identified confidence intervals confirm the trends of dominating to positive attitude statements in respondents' answers and achieved high level of explicitly of the choice made and consent with the positively oriented in valued and content aspect statements and related to them attitudes.

9. No statistically significant differences identified between the compared male and female respondents' sample regarding the attitudes towards persons with disabilities in the analysed six fields. The presented data reveals the relative unity in the stated positions of the male and female gender respondents, as well as the explicitness of the expressed by them opinions and the agreement with statements from the scale related to certain attitudes.

10. There was no evidence identified of statistically significant differences between the compared samples of answers of respondents' from the Bulgarian and Turkish ethnic communities in relation to attitudes towards persons with disabilities in the analysed six fields and the elements included in them (Table 3). This allows the opinions expressed by the two samples of respondents on statements in fields and elements contained in them, to define as characterized by the absence of significant differences, expressed explicitness and consent with the statements of certain attitudes.

11. Statistically significant differences between compared samples of respondents with and without a person with disability in the family or in the family environment, in terms of attitudes towards persons with disabilities were not been found in five (Fields 2, $3,4,5$ and 6 ). The minimum value of the difference in Field 1 reveals a stronger agreement among respondents with a person with disability in the family or in the family environment on issues in the field.

Table 3. Statistics of Mann-Whitney U-test by areas to depending on the indicator "identification with ethnic community"

\begin{tabular}{|l|l|l|l|l|l|l|}
\hline \multicolumn{7}{|l|}{ Test Statistics } \\
\hline & Field 1 & Field 2 & Field 3 & Field 4 & Field 5 & Field 6 \\
\hline Mann-Whitney U & 862,500 & 822,000 & 757,000 & 718,000 & 915,500 & 871,000 \\
\hline Wilcoxon W & 1642,500 & 1602,000 & 1537,000 & 1459,000 & 1695,500 & 2047,000 \\
\hline Z & $-0,631$ & $-0,991$ & $-1,533$ & $-1,692$ & $-0,176$ & $-0,605$ \\
\hline Asymp. Sig. (2-tailed) & 0,528 & 0,321 & 0,125 & 0,091 & 0,860 & 0,545 \\
\hline \multicolumn{2}{|l|}{ a. Grouping Variable: Identification with ethnic community } \\
\hline
\end{tabular}

12. Statistically significant differences between the compared samples of respondents who have and who have no friends with disabilities in terms of attitudes towards persons with disabilities not found in the six fields. The chosen by respondents from the two samples statement of certain attitudes towards persons with disabilities characterized by a high level of expressed consent and unity in positions. The quantitative and qualitative analysis of empirical data by fields of the research tool provides the opportunity to present the following summary results for the attitudes towards persons with disabilities formed up in the context of an educational and social environment with an anti-discrimination component.

1. High values of the relative shares of respondents' answers to statements in the elements of all fields for positive non-discriminatory attitudes towards persons with disabilities are identify. Exist sustained overall trend of their distribution within a narrow range and predominantly on the left side of the scale sector (on average from $54.3 \%$ to $96.3 \%$ ) and with strong dominance of relative shares of full consent. The positive trend most strongly presented in Field 2 (Figure 1). 


\begin{tabular}{llllll} 
& ISRA (India) $=\mathbf{3 . 1 1 7}$ & SIS (USA) & $=\mathbf{0 . 9 1 2}$ & ICV (Poland) & $=\mathbf{6 . 6 3 0}$ \\
Impact Factor: & ISI (Dubai, UAE) $=\mathbf{0 . 8 2 9}$ & PUHL (Russia) $=\mathbf{0 . 1 5 6}$ & PIF (India) & $=\mathbf{1 . 9 4 0}$ \\
& GIF (Australia) $=\mathbf{0 . 5 6 4}$ & ESJI (KZ) & $=\mathbf{8 . 7 1 6}$ & IBI (India) & $=\mathbf{4 . 2 6 0}$ \\
& JIF & $\mathbf{1 . 5 0 0}$ & SJIF (Morocco) $=\mathbf{5 . 6 6 7}$ & OAJI (USA) & $\mathbf{0 . 3 5 0}$ \\
\hline
\end{tabular}

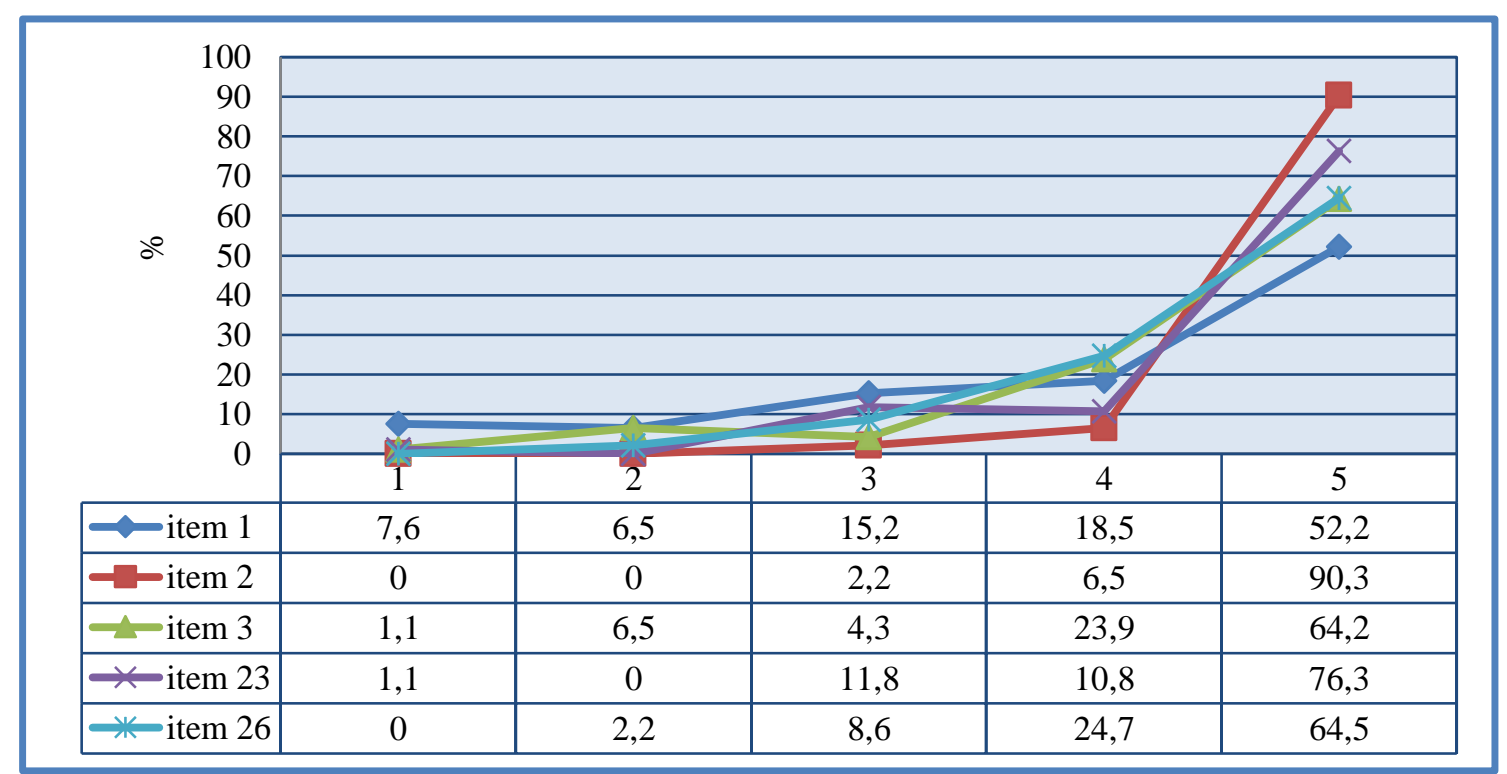

Figure 1. Attitudes of students towards persons with disabilities in the items of Field 2 (results reported on a 5-point Likert scale)

In three of the analysed fields with content related to some taboo and myths and prejudices, and generating variations and controversy, there is a minimal increase in the relative shares of neutral answers, which accompanied by a very low share of positions of negative attitudes. The resulting insignificant internal dynamics dominated by the high values of the relative shares of responses to positive attitudes on the rest of the elements, and a positive overall trend emerges. Quantitative and qualitative analysis data together with the presented statistical arguments provide an opportunity to prove the positive non-discriminatory attitudes of the social work students to on items in Field 1.

2. The relative share of respondents' statements of negative attitudes in the fields surveyed characterized by low values and variations in narrower ranges. In elements in some certain fields no were expressed dissents and in others there is no dissent with a certain level of uncertainty. This is accompanied by low values of the shares of presented neutral positions and with several times higher values of the shares of responses for positive nondiscriminatory attitudes. The quantitative and qualitative information presented in comparative aspect and related statistical evidence provide an opportunity to claim the ascertainment of a persistent tendency of a positive orientation of students' attitudes in the fields of the research tool and its interpretation as a significant outcome in educational and social aspect.

3. Respondents' answers expressing a neutral position to statements of certain attitudes in the fields of the research tool have relatively low shares and characterized by a relatively even distribution in an interval of insignificant dynamics. The quantitative and qualitative analysis and statistical evidence presented in all fields revealed high relative values and dominance of the relative shares of positive attitudes responses to a significant extent over the values of the respondents with expressed neutral opinion.

4. Belonging to the male or female gender, identification with a Bulgarian or Turkish ethnic community and the presence or absence of a friend or friends who are disabled, have no influence generating significant differences in the degree of consent with chosen by the respondents from the compared groups statements of attitudes toward persons with disabilities.

5. The impact of belonging to a particular religious community as a factor in the given educational and social environment characterized by minimal dynamics in two of the fields (Field 3 and 4). The minimal difference between the compared groups of respondents may related to the assumption of a presence under some participants in the research of difficult to overcome influences of religious beliefs and related stereotypes and disability-based prejudices, requiring longer work on their transformation and positivation. In general plan this does not have impact, capable of generating significant differences in the power of consenting to statements of attitudes towards persons with disabilities from respondents of both religious groups. 


\begin{tabular}{llllll} 
& ISRA (India) $=\mathbf{3 . 1 1 7}$ & SIS (USA) $=\mathbf{0 . 9 1 2}$ & ICV (Poland) & $\mathbf{= 6 . 6 3 0}$ \\
Impact Factor: & ISI (Dubai, UAE) $=\mathbf{0 . 8 2 9}$ & PUHЦ (Russia) $=\mathbf{0 . 1 5 6}$ & PIF (India) & $=\mathbf{1 . 9 4 0}$ \\
& GIF (Australia) $=\mathbf{0 . 5 6 4}$ & ESJI (KZ) & $\mathbf{8 . 7 1 6}$ & IBI (India) & $=\mathbf{4 . 2 6 0}$ \\
& JIF & $\mathbf{1 . 5 0 0}$ & SJIF (Morocco) $=\mathbf{5 . 6 6 7}$ & OAJI (USA) & $\mathbf{0 . 3 5 0}$ \\
\hline
\end{tabular}

6. Significant differences in relation to the power of expression of consent in the choice of positions for attitudes towards persons with disabilities between the compared groups of respondents with and without a person with a disability in the family or in the family environment not found in five of the fields. There are minimal differences in one field (Field 1). The assumption is that this is the result of greater experience and better awareness of respondents with a person with disability in the family or in the family environment. They have a stronger agreement on issues related to the interpretation of the nature of disability in the context of modern concepts, interaction between persons with and without disabilities and the promotion and facilitation of their social integration, opportunities for independent living of persons with disabilities, dependence of persons with disabilities on care. Presented situation gives rise to insignificant dynamics that in general does not create conditions for significant differences and reveals the presence of a relative unity in expressing positions of certain attitudes towards persons with disabilities.

\section{Discussion}

The results of the statistical, quantitative and qualitative analysis of data from the empirical research allows summarizing that there was established enough evidence of forming in the conditions of the model of educational and social environment with an anti-discrimination component in the social work students' positive nondiscriminatory attitudes toward persons with disabilities. This contributes to improving the quality and effectiveness of training at the following main points:

a. absorption by students of a system of values, knowledge, skills and practical experience in a general and antidiscrimination aspect, promoting the adoption and implementation of the concepts of diversity, equality, tolerance, non-discrimination in the field of disability and in other spheres, accordance with their professional and social timeliness and importance, their internalization and realization in a conscious in a valued and professional aspect models of behaviour, activities and interactions in formal and informal interpersonal systems in the academic environment, community and society;

b. formation and functioning of an educational, and social environment with an anti-discrimination context, characterized by sensitivity towards disabilities and differences on another basis, with an active and professionally acknowledged attitude of tolerance, equality and non-discrimination, focusing on achieving significant in value, affective, cognitive, behavioural and activeness aspect results in the preparation of social work students in its antidiscrimination perspective;

c. training of social workers to antidiscrimination competence capable of guiding the best interests of clients, the protection of their rights and freedoms, and the provision of assistance characterized by sensitivity to discriminatory signs;

d. construction of a favourable educational and social environment and a cognitive context with an anti-discriminatory perspective, which in synthesis contribute to the formation of professional, antidiscrimination and cultural competences;

e. formation of an active professional, civic and social position, contributing to: initiating and implementing changes in social and antidiscrimination legislation, policies and practices;

f. integrating anti-discrimination professional, civic and social position, creating the conditions for forming a broad anti-discrimination platform for affirmation in the educational and professional activity and in the society of diversity, equality, tolerance and non-discrimination.

\section{Conclusion}

The results of the research allow revealing the relevance and importance of creating in innovative social work education model conditions for forming positive non-discriminatory attitudes in the students toward persons with disabilities. This contribute to the accepting in valued and professional aspect in and through realized activities and interactions in different interpersonal, formal, and informal social systems of contemporary conception of disability. It includes diversity in society and the principles of equality, tolerance and non-discrimination in the area of disability and other related to it with orientation to their sustainable integration in an internal aspect and their subjecting in models of tolerant and nondiscriminatory behaviour in the academic environment, community and society. Active and motivated involvement of social work students in activities and interactions in educational and social environment with an anti-discrimination component is stimulates. This contributes to formation of cultural competence in the area of disability as an element of professional competence and realization of important in value, affective, cognitive, behavioural and actionoriented aspect achievements in training on social work. Students acquire a deeper knowledge of antidiscrimination problematic and perspectives in social work in the contemporary dynamic social, political, economic, demographic and cultural context, which oriented towards realization of quality education and training in social work in accordance with modern disability paradigms and with professional and public needs at national and European level. 


\begin{tabular}{llllll} 
& ISRA (India) $=\mathbf{3 . 1 1 7}$ & SIS (USA) & $=\mathbf{0 . 9 1 2}$ & ICV (Poland) & $=\mathbf{6 . 6 3 0}$ \\
Impact Factor: & ISI (Dubai, UAE) $=\mathbf{0 . 8 2 9}$ & PUHL (Russia) $=\mathbf{0 . 1 5 6}$ & PIF (India) & $=\mathbf{1 . 9 4 0}$ \\
& GIF (Australia) $=\mathbf{0 . 5 6 4}$ & ESJI (KZ) & $=\mathbf{8 . 7 1 6}$ & IBI (India) & $=\mathbf{4 . 2 6 0}$ \\
& JIF & $\mathbf{1 . 5 0 0}$ & SJIF (Morocco) $=\mathbf{5 . 6 6 7}$ & OAJI (USA) & $\mathbf{0 . 3 5 0}$ \\
\hline
\end{tabular}

\section{References:}

1. Allport, G. W. (1954). The nature of prejudice. Cambridge, MA: Perseus Books.

2. Antonak, R. (1992). Scale of Attitudes toward Disabled Persons (SAPD). Form R. Durham, NH: University of New Hampshire.

3. Antonak, R. F., \& Livneh, H. (1988). The measurement of attitudes toward people with disabilities: Methods, psychometrics and scales. Springfield, Illinois: Charles C. Thomas.

4. Antonak, R. F., \& Livneh, H. (2000). Measurement of attitudes towards persons with disabilities. Disability and Rehabilitation: An International, Multidisciplinary Journal, 22(5), 211-224.

http://dx.doi.org/10.1080/0963828002967 82

5. (2006). Convention on the Rights of Persons with Disabilities (CRPD). Optional Protocol (A/RES/61/106). United Nations, General Assembly, 13 December 2006.

6. Davies, K., Tropp, L. R., Aron, A., Pettigrew, T. F., \& Wright, S. C. (2011). Cross-group friendships and intergroup attitudes: A metaanalytic review. Personality and Social Psychology Review, 15(4), 332-351. https://doi.org/10.1177/ 1088868311411103

7. Dovidio, J., Gaertner, S., \& Kawakami, K. (2003). Intergroup contact: The past, present, and the future. Group Processes \& Intergroup Relations, 6(1), 5-21. https://doi.org/10.1177/ 1368430203006001009

8. (2018). European Association of Schools of Social Work, News. Regional forum with international participation for good educational and professional practices on social work University of Ruse. Retrieved from: https://www.eassw. org/regional-forum-withinternational-participation-for-goodeducational-and-professional-practices-onsocial-work-in-university-of-ruse/

9. (2018). European Association of Schools of Social Work, News. Social work students in University of Ruse, Bulgaria celebrated the international day of the rights of the disabled people with a flash mob. Retrieved from: https://www.eassw.org/social-work-students-inuniversity-of-ruse-bulgaria-celebrated-theinternational-day-of-the-rights-of-the-disabledpeople-with-a-flash-mob/

10. (2015). European Parliament resolution of 20 May 2015 on the List of Issues adopted by the United Nations Committee on the Rights of Persons with Disabilities in relation to the initial report of the European Union (2015/2684(RSP)).

11. Pettigrew, T. F. (1998). Intergroup contact theory. Annual review of psychology, 49 (1), 65 85.

https://doi.org/10.1146/annurev.psych.49.1.65

12. Pettigrew, T. F., \& Tropp, L. R. (2008). How does intergroup contact reduce prejudice? Metaanalytic tests of three mediators. European Journal of Social Psychology, 38 (6), 922-934. http://dx.doi.org/10.1002/ejsp.504 